\title{
Discrimination learning in chicks previously exposed to the discriminanda
}

\author{
D. J. STEWART, P. J. CAPRETTA, and A. J. COOPER \\ Miami University, Oxford, Ohio 45056
}

\begin{abstract}
Three experiments are described. The ability of chicks to discriminate shape or colored stimuli after being exposed to both discriminanda in an imprinting situation is compared with the discriminative ability of chicks not previously exposed. In two of the three experiments, we found no differences between the groups, although in the third, the group previously exposed to the discriminanda showed an impairment in discriminative ability. Our negative results are not in accordance with those of Bateson and Chantrey (1972), who attribute the learning impairment to a prior "classifying together" of the stimuli, a mechanism enabling the chick to respond to differing views of the imprinting object as representative of the same object.
\end{abstract}

It has recently been reported (Bateson \& Chantrey, 1972: Chantrey, 1972, 1974) that the ability of chicks to learn a color discrimination can be impaired if the chicks have previously been exposed to the discriminanda. For $1 \mathrm{~h}$ each day during the first 5 days after hatching, the chicks were presented with moving colored cylinders. They were later trained in a Y-maze, and it was found that, when chicks were required to choose between two colors, those that had previously been exposed to cylinders of these two colors learned less rapidly than chicks exposed to cylinders of a third, different color. Prior exposure to only one of the colors to be discriminated facilitated learning. These findings were interpreted by Bateson and Chantrey (1972) in terms of the way in which a young bird might learn the characteristics of an imprinting object. The mother hen, to whom the attachment is usually formed, provides a number of stimuli to the chick as she moves about, and the chick must respond to all of these stimuli as representative of the same object. Varying, sequentially occurring images come to be "classified together," in Bateson and Chantrey's terminology, and subsequently are not readily discriminated.

The studies represent the first evidence to show that imprinting involves the building up of a composite image of the imprinting object rather than a "stamping in" of the object's characteristics; additionally, Chantrey (1974) suggests that "classifying together" may be an integral part of the process by which all animals acquire "object constancy."

Three experiments of a series of studies originally designed to replicate and extend these findings are reported.

\section{METHODS}

\section{Experiment 1}

The subjects were 40 Shaver Starcross Leghorn chicks, but

D. J. Stewart is now at Corner-Brook Regional College of Memorial University of Newfoundland, Corner Brook, Newfoundland, Canada. deaths and our inability to train some of these reduced the number to 27 . The chicks were incubated in darkness and, after hatching, were marked for identification purposes and housed individually in a brooder. Initial brooder temperature was $33^{\circ} \mathrm{C}$; this was reduced steadily as the experiment proceeded. The brooder was covered with a blanket; the inside was constantly illuminated by a faint nonpatterned light.

The exposure apparatus consisted of an elongated rectangular alleyway $(178 \mathrm{~cm}$ long $\times 15 \mathrm{~cm}$ wide $\times 29 \mathrm{~cm}$ high) painted a uniform gray. A $15-\mathrm{W}$ white bulb was fitted at each end, and the exposure stimuli were positioned in front of them. The stimuli were shapes cut from a panel of Masonite; the panels fitted in slats across the alleyway. The panels were backed with white paper, so the stimuli were evenly illuminated in white light when the bulbs were lit.

The subjects were divided into four groups. Groups A and B (experimental) were exposed to circles and squares (buth stiniuli were visible at each end); $A$ was trained to square ${ }^{+}$circle $^{-}$and $B$ to circle $^{+}$square $^{-}$. Groups $C$ and D (control) were exposed to triangles (two at each end); $C$ was later trained to square ${ }^{+}$ circle $^{-}$and $D$ to circle ${ }^{+}$square $^{-}$. Thirty-minute exposure was given on Day 1 and Day 2 after hatching. The chicks were allowed to approach the lighted stimuli at one end; on reaching a line $10 \mathrm{~cm}$ from them, the light was turned off, while the light behind the stimuli at the other end was turned on. This was repeated as often as the chick approached either end.

On Days 3 and 4, the chicks were pretrained in the discrimination apparatus, which consisted of a rectangular box (91 x $32 \times 29 \mathrm{~cm}$ high) painted gray inside. Two goal alleys were formed in one end by a division projecting $30 \mathrm{~cm}$ from the midpoint of the wall. The discriminanda were shapes of the same size as those in the exposure apparatus, cut in panels backed with paper, and lit from behind. A startbox was formed by two divisions extending $15 \mathrm{~cm}$ into the apparatus from the opposite wall. Pretraining involved allowing each chick food deprived to eat starter mash from each goalbox for up to 30 min each day without the discriminanda being present.

On Day 5 discrimination training began. Each chick (10-h food deprived) was given 10 runs/day on 6 consecutive days or a $9 / 10$ criterion. With both stimuli illuminated, chicks were required to discriminate circles and squares. Food pots were placed in front of each panel; that in front of the correct stimulus contained starter mash. Interrun interval was $30 \mathrm{sec}$, with up to $3 \mathrm{~min}$ allowed per run. Chicks not eating in the $3 \mathrm{~min}$ were placed in the correct goalbox and allowed to eat for a few seconds. The position (left/right) of the correct stimulus was randomly varied across runs.

\section{Experiment 2}

This differed from Experiment 1 in the following ways: The 
Table 1

Learning by Chicks Exposed to Shape Stimuli: Experiment 1

\begin{tabular}{llcccc}
\hline Group & N & $\begin{array}{c}\text { Mean Trials } \\
\text { to Criterion }\end{array}$ & H & p \\
\hline A & 7 & 32.4 & & \\
B & 6 & 40.2 & 2.67 & n.s. \\
C & 6 & 31.0 & & \\
D & 8 & 42.4 & & \\
\hline
\end{tabular}

subjects were 16 chicks of the same strain. After hatching they were placed in a communal brooder.

The exposure apparatus closely resembled that of Chantrey (1972). It consisted of a ring of 12 radially arranged pens, with outer walls formed by wire. The floors, side wall, rear wall, and roof of the pen were gray. Light was provided by a $200-\mathrm{W}$ bulb $3 \mathrm{~m}$ above the apparatus. The stimuli were cardboard cylinders hung from four spokes projecting over the tops of the pens. The cylinders rotated at $1 \mathrm{rpm}$ and thus were in front of each pen for $5 \mathrm{sec}$ on each revolution. The cylinders were viewed against a gray outer wall. The chicks were divided into four groups. Groups $A^{\prime}$ and $B^{\prime}$ (experimental) were exposed to alternate red and blue cylinders; $A^{\prime}$ was later trained to red + blue ${ }^{-}, B^{\prime}$ to blue ${ }^{+}$red-. Groups $C^{\prime}$ and $D^{\prime}$ (control) were exposed to green cylinders only; $C^{\prime}$ was later trained to red $^{+}$ blue $^{-}, \mathrm{D}^{\prime}$ to blue ${ }^{+}$red-. Each chick received $1 \mathrm{~h} /$ day in this apparatus on Days 1-5, which amounted to $100 \mathrm{~min}$ of actual exposure. On Day 6 the chicks were "shaped" in the discrimination apparatus-by releasing them, food deprived, from positions successively farther from the food pots. On Days 7-11 they were trained to discriminate panels of red and blue. The discrimination apparatus differed only slightly from that used in Experiment 1 . Dimensions were $90 \times 30 \times 30 \mathrm{~cm}$; the startbox was provided with a sliding door. After $22 \mathrm{~h}$ of food deprivation, chicks were given 20 runs/day to a criterion of $18 / 20$. First-run choice latency was also recorded. No correction procedure was used.

\section{Experiment 3}

The subjects were 18 Vantress broiler chicks, divided into two groups. Group $A^{\prime \prime}$ (experimental) was exposed to red and blue cylinders and trained to blue ${ }^{+}$red-; Group B" (control) was exposed to green cylinders and trained to blue ${ }^{+}$red- also. Rearing conditions and other procedural details were as in Experiment 2, except that an error delayed pretraining by 1 day-to Day 8 . The deaths of three chicks reduced final group sizes to six and seven.

\section{RESULTS}

Results are given in Tables 1,2 , and $3 . \mathrm{H}$ values are from the Kruskal-Wallis test, and $U$ values are from the Mann-Whitney test. In Experiment 1 no differences were found between discrimination performance of chicks previously exposed to the shape discriminanda (Groups A and B) and that of the chicks not so exposed (Groups $C$ and D), as shown in Table 1.

The results of Experiment 2 were also negative, in that preexposure to the colored discriminanda failed to impair later discriminative ability. Groups $A^{\prime}$ and $B^{\prime}$ reached criterion in a mean of 50.75 trials; Groups $C^{\prime}$ and $\mathrm{D}^{\prime}$ in a mean of 58.7 trials. The color designated correct did, however, influence learning speed. Groups $\mathrm{A}^{\prime}$ and $\mathrm{C}^{\prime}$ (run to red) took significantly more trials to criterion (75.1) than Groups $B^{\prime}$ and $D^{\prime}$ (run to blue, 34.4). Groups $A^{\prime}$ and $B^{\prime}$ did, however, show significantly lower first-run approach latencies $(17.2 \mathrm{sec})$ than did groups $\mathrm{C}^{\prime}$ and $\mathrm{D}^{\prime}(70.8 \mathrm{sec})$, demonstrating that exposure had resulted in "imprinting." These results are given in Table 2.

Experiment 3 produced results at variance with those of Experiment 2. Exposure to the discriminanda did result in retarded discrimination performance. Group A" took a mean of 45.5 trials to criterion, compared to a mean of 27.7 trials in Group B". However, the groups did not vary in terms of first-run approach latencies, as they did in Experiment 2 (Group $\mathrm{A}^{\prime \prime}$ mean $=35.2 \mathrm{sec}$, Group $B^{\prime \prime}$ mean $\left.=23.4 \mathrm{sec}\right)$. These results are given in Table 3.

\section{DISCUSSION}

The phenomenon of "classifying together" was proposed by Bateson and Chantrey (1972) as a mechanism whereby young animals acquire object constancy, making the "classified together" being subsequently less easily discriminated. We felt, initially, that such a general and important effect would be obtainable from a range of experimental situations. Procedurally, our first study bore little resemblance to theirs. Its negative outcome, however, caused us to attempt to replicate theirs more closely. The subsequent failure of Experiment 2 led to a series of further studies, to be reported later. Only in the first of these (the third reported here) was the impairment in discrimination performance obtained.

Despite the great differences between our first experiment and those of Bateson and Chantrey, the experimental chicks were simultaneously exposed in the alleyway to both of the stimuli later to be discriminated, a situation seemingly most favorable for the occurrence of "classifying together." This did not, however, occur.

Our second experiment, a much closer replication, also ended

Table 2

Learning by Chicks Exposed to Color Stimuli: Experiment 2

\begin{tabular}{|c|c|c|c|c|c|}
\hline & \multicolumn{5}{|c|}{$\begin{array}{c}\text { Mean Trials } \\
\text { to }\end{array}$} \\
\hline & Group & $\mathbf{N}$ & Criterion & $\mathrm{U}$ & p \\
\hline $\begin{array}{l}\text { Effects of exposure } \\
\text { vs. nonexposure }\end{array}$ & $\begin{array}{l}A^{\prime} B^{\prime} \\
C^{\prime} D^{\prime}\end{array}$ & $\begin{array}{l}8 \\
8\end{array}$ & $\begin{array}{l}50.75 \\
58.7\end{array}$ & 30.5 & n.s. \\
\hline $\begin{array}{l}\text { Effects of training } \\
\text { color }\end{array}$ & $\begin{array}{l}A^{\prime} C^{\prime} \\
B^{\prime} D^{\prime}\end{array}$ & $\begin{array}{l}8 \\
8\end{array}$ & $\begin{array}{l}75.1 \\
34.4\end{array}$ & 2.0 & $<.01$ \\
\hline $\begin{array}{l}\text { Approach latency } \\
\text { Run } 1(\mathrm{sec})\end{array}$ & $\begin{array}{l}A^{\prime} B^{\prime} \\
C^{\prime} D^{\prime}\end{array}$ & $\begin{array}{l}8 \\
8\end{array}$ & $\begin{array}{l}17.2 \\
70.8\end{array}$ & 11.0 & $<: 05$ \\
\hline
\end{tabular}

Table 3

Learning by Chicks Exposed to Color Stimuli: Experiment 3

\begin{tabular}{|c|c|c|c|c|c|}
\hline & Group & $\mathbf{N}$ & $\begin{array}{c}\text { Mean } \\
\text { Trials } \\
\text { to } \\
\text { Criterion }\end{array}$ & $\mathbf{U}$ & $\mathrm{p}$ \\
\hline $\begin{array}{l}\text { Effects of exposure } \\
\text { vs. nonexposure }\end{array}$ & $\begin{array}{l}\mathrm{A}^{\prime \prime} \\
\mathrm{B}^{\prime \prime}\end{array}$ & $\begin{array}{l}6 \\
7\end{array}$ & $\begin{array}{l}45.5 \\
27.7\end{array}$ & 6.5 & $<.05$ \\
\hline $\begin{array}{l}\text { Approach latency } \\
\text { Run } 1 \text { (sec) }\end{array}$ & $\begin{array}{l}\mathrm{A}^{\prime \prime} \\
\mathrm{B}^{\prime \prime}\end{array}$ & $\begin{array}{l}6 \\
7\end{array}$ & $\begin{array}{l}35.2 \\
23.4\end{array}$ & 12.0 & n.s. \\
\hline
\end{tabular}


negatively, although the first-run approach latency of the experimental groups was lower than that of the controls. In the third experiment, a virtual rerun of the second, the learning retardation occurred, but the "imprinting" effect did not.

Certain procedural differences between Bateson and Chantrey's work and ours should be mentioned. Instead of Ross broilers, we used two strains of chicks; the effect was seen once (but not subsequently) only in the Vantress broilers. We did not use a light/dark cycle; our chicks fared better in continuous lighting.

The results are of significance, if only in suggesting that the conditions under which the phenomenon occurs remain to be clearly demonstrated. Imprinting toward the exposure object does not seem to be necessary to produce the slower learning. In our third experiment, in which the learning impairment was found, the approach latency of the experimental chicks did not differ from that of the controls. Also in this experiment, the differences between the groups seemed to be less the result of slow learning on the part of the exposed chicks than of exceptionally rapid learning on the part of the controls, who reached criterion of $18 / 20$ in 27.7 trials run to blue. The learning deficit in this experiment might be explained in terms of an initial preference for blue over red being attenuated by exposure to those colors. It should be pointed out that Chantrey (1972) obtained the discrimination impairment only when chicks were run with blue correct.

In sum, we must remain skeptical about the impairment in discrimination brought about by "classifying together." Impairment is less robust and more situation dependent than hitherto reported.

\section{REFERENCES}

Bateson, P. P. G., \& Chantrey, D. F. Retardation of discrimination learning in monkeys and chicks previously exposed to both stimuli. Nature, 1972, 237, 173-174.

Chantrey, D. F. Enhancement and retardation of discrimination learning in chicks after exposure to the discriminanda. Journal of Comparative and Physiological Psychology, 1972, 81, 256-261.

Chantrey, D. F. Stimulus pre-exposure and discrimination learning by domestic chicks. Journal of Comparative and Physiological Psychology, 1974, 87, 517-525.

(Received for publication July $11,1976$. ) 